\title{
Supporting the Development of Shared Understanding In Distributed Design Teams
}

Philip Cash* $^{*}$, Elies Dekoninck ${ }^{2}$, Saeema Ahmed-Kristensen ${ }^{1}$

To cite this article: Philip Cash, Elies A Dekoninck \& Saeema Ahmed-Kristensen (2017) Supporting the development of shared understanding in distributed design teams, Journal of Engineering Design, 28:3, 147-170, DOI: 10.1080/09544828.2016.1274719

To link to this article: http://dx.doi.org/10.1080/09544828.2016.1274719

${ }^{1}$ Departement of Management Engineering, DTU, Denmark

${ }^{2}$ Department of Mechanical Engineering, University of Bath, UK

Journal of Engineering Design

* Corresponding author contact details:

Philip Cash

Department Of Management Engineering

Technical University of Denmark

DK-2800 Lyngby, Denmark

Tel: $\quad+4545254550$

Email: $\quad$ pcas@dtu.dk

Fax: NA 


\title{
Supporting the Development of Shared Understanding In Distributed Design Teams
}

\begin{abstract}
Distributed teams are an increasingly common feature of engineering design work. One key factor in the success of these teams is the development of short and longer-term shared understanding. A lack of shared understanding has been recognized as a significant challenge, particularly in the context of globally distributed engineering activities. A major antecedent for shared understanding is question asking and feedback. Building on question asking theory this work uses a quasi-experimental study to test the impact of questioning support on homogeneous and heterogeneous teams. The results show significant improvement in shared understanding for both team types ( $27 \%$ improvement for heterogeneous and $16 \%$ for homogeneous), as well as substantial differences in how this improvement is perceived. This extends theoretical insight on the development of shared understanding and contributes one of few empirical studies directly comparing homogeneous and heterogeneous teams in the engineering design context. This has implications for how distributed teams can be more effectively supported in practice, as well as how shared understanding can be facilitated in engineering design.
\end{abstract}

Keywords: Distributed design, communication; planning, teamwork, design studies

\section{Introduction}

Communication and the development of shared understanding in engineering design teams is an area of sustained importance for both research and industry. This is due to its impact on long-term performance (Eris, Martelaro, and Badke-Schaub 2014; Tang, Lee, and Gero 2011), as well as the increase in globally distributed engineering design activities (Hansen, Zhang, and Ahmed-Kristensen 2013). In particular, there is an growing reliance on communication support tools in distributed design work (Maznevski and Chudoba 2000; Hinds and Mortensen 2005). A number of researchers have examined distributed team communication and the development of shared understanding (Eris, Martelaro, and Badke-Schaub 2014; 
McComb, Green, and Dale Compton 1999). However, these have typically focused on either homogeneous e.g. Chiu et al.'s (2006) examination of student virtual communities, or heterogeneous teams e.g. Bittner and Leimeister's (2013) study of shared process planning. Here, homogeneity refers to team composition with respect to cultural background, education, experience, and other demographic factors. Further, research in the systems engineering and software development domains points to the need to balance team goals (McComb, Green, and Dale Compton 1999; McComb 2007) and role differentiation (Levesque, Wilson, and Wholey 2001) in order to sustain shared understanding. The dynamic development of goals and roles can differ across homogeneous and heterogeneous teams (Chatman and Flynn 2001). Thus there are a number of key questions regarding shared understanding development in the two types of teams, which inform the subsequent design of communication support tools (Johnson et al. 2007).

Shared understanding is a key measure of communication effectiveness in distributed teams (Humayun and Gang 2013; Johnson and O'Connor 2008). This is influenced by factors including social interaction (Chiu, Hsu, and Wang 2006), quality of communication (Maznevski and Chudoba 2000), and shared context (Humayun and Gang 2013; Hinds and Mortensen 2005). Further, Herbsleb (2007) (in the software systems domain) highlights the elicitation and communication of requirements, and the orchestration of development, as key issues affected by shared understanding, which are critically linked to similar challenges in the engineering design domain (Hansen, Zhang, and Ahmed-Kristensen 2013). Drawing together prior research in engineering design (Dong 2005; Deken et al. 2012) and other domains (DeFranco, Neill, and Clariana 2011; McComb 2007) points to key questions surrounding heterogeneity and the development of shared understanding, particularly in planning type tasks. 
Decomposing the mechanisms by which varying degrees of heterogeneity effect team performance reveals a number of variables including, culture (Matveev and Nelson 2004), education (Humayun and Gang 2013), and demographics (Lau and Murnighan 1998). However, how these variables effect the impact of communication support on shared understanding development across homogenous/heterogeneous teams has been little explored (Lawler and Yoon 1996; Hinds and Mortensen 2005). As such, this work aims to directly test key hypotheses in this context via a comparative quasi-experimental study.

The paper is structured as follows. Section 2 describes the research framework and hypotheses. Section 3 then defines the study methodology. Subsequently, Section 4 outlines the results before key implications are identified and discussed in Section 5.

\section{Research Framework and Hypotheses}

This section outlines the theoretical background for the work. First, the key variables: team composition, shared understanding development, and question asking/feedback, are described and linked in Section 2.1. Second, the theoretical interaction between variables is used to define specific hypotheses in Section 2.2.

\subsection{Research Framework: Team Composition and Shared Understanding}

Team performance and heterogeneity are critically connected (Faems and Subramanian 2013). In particular cultural and educational diversity have been linked to innovation, creativity, and flexibility (Kochan et al. 2003; Auh and Menguc 2005). Here, culture is a composite construct reflecting influences from global and national outlook (Erez and Gati 2004). Systematic review reveals numerous sub-factors within cultural diversity, with little consensus on their combination or primacy (Leidner and Kayworth 2006). One relatively accepted means for assessing culture is the work of Hofstede et al. (2010) where a national 
level approximation is used. In this context diverse perspectives are associated with e.g. improved creativity (Wodehouse and Maclachlan 2014), but at the cost of reduced shared understanding and the need for culturally intelligent leadership (Ang and Inkpen 2008). Similarly, educational diversity comprises a number of dimensions including specific background and level (Joshi and Roh 2009), which are particularly important in developing a range of skills, views, and ways of understanding and evaluating (Barkema and Shvyrkov 2007; Auh and Menguc 2005). This diversity of insight within teams has again been linked to improved innovation, creativity, and flexibility (Carpenter and Fredrickson, J 2001). However, researchers also highlight that this diversity reflects divergence between mental models within a team (Auh and Menguc 2005) making the development of shared understanding more difficult (Bittner and Leimeister 2013). Together cultural and educational diversity have a significant impact on team performance, distinct from other demographic factors (e.g. gender or age) (Dahlin, Weingart, and Hinds 2005; Kochan et al. 2003). However, there are no direct means for systematically combining dimensions of heterogeneity. As such, this work follows prior research in considering cultural and educational diversity as key moderators of heterogeneity in engineering design teams (Cash et al. 2015), and explores the connection between heterogeneity and shared understanding development (Badke-Schaub et al. 2007).

A key means of addressing the negative effects of team diversity has been the development of communication support tools aimed at fostering the development of team shared understanding e.g. by helping to align varied mental models. In this context, shared understanding has been shown to affect performance across disciplines, team types, and work foci (Chiu, Hsu, and Wang 2006; Preston, Karahanna, and Rowe 2006). It plays an important role in both organisation level performance (together with information acquisition and knowledge exchange) (Hult, Ketchen, and Slater 2004; Carson, Tesluk, and Marrone 2007), 
and individual/team level performance (Badke-Schaub et al. 2007; Bittner and Leimeister 2013). Further, shared understanding combines a number of sub-elements including: shared vision e.g. goals and ambition (Chiu, Hsu, and Wang 2006), solution understanding e.g. the concept developed (Preston, Karahanna, and Rowe 2006), and role distribution understanding e.g. each team members' responsibilities and areas of concern (Badke-Schaub et al. 2007). Hinds and Mortensen (2005) break down the components contributing to overall shared understanding as: shared context, work culture, information, work processes, and tools. These have been addressed by a number of support approaches, including concept mapping and question asking support (Mulder, Swaak, and Kessels 2004). However, Johnson et al.'s (2007) review of team-related knowledge sharedness emphasises the need to support both task and team related knowledge sharing. Further, Johnson et al. (2007) highlight the following question: how can shared understanding support be effectively deployed in both heterogeneous and homogeneous teams? Specifically, Johnson et al. (2007) infer that there are differences in how heterogeneous and homogenous teams should be supported to increase shared understanding. Despite these differences, question asking has been shown to be a key component of shared understanding development across contexts and team types (Mulder, Swaak, and Kessels 2004).

Question asking is considered a core contributor to shared understanding development, with studies of design work highlighting its significance in problem solving and in the application of different design strategies (Eris 2002; Aurisicchio, Bracewell, and Wallace 2006; Ahmed, Wallace, and Blessing 2003). In particular, design engineers progress their tasks by asking questions at both reasoning and strategic levels (Aurisicchio, Ahmed, and Wallace 2007). Further, Dym et al. (2005) identified the benefits of a questioning centric thinking process when exploring the concept domain. Eris (2002) identified 22 question classes and divides these into two groups: Deep Reasoning Questions and Generative Design 
Questions. Here, deep reasoning questions focus on understanding facts, while generative questions focus on creating possibilities. These studies all highlight the potential importance of question asking in the development of shared understanding across all design activities, however, they have typically focused on problem solving tasks.

Bringing together the literature on team composition, development of shared understanding, and question asking in design, the following research framework is proposed, illustrated in Figure 1. Here, questioning and feedback are related in a cyclical process of exchange and negotiation (Eris 2002), mediated by communication support (Mulder, Swaak, and Kessels 2004), and occurring within the context of the team composition. The dynamic interaction between these elements leads to the development and perception of shared understanding within a team. This provides a distinct and bounded dependant variable underpinned by a cyclical process of question asking and feedback activity, which provides a specific target for communication support interventions. Further, question asking and feedback provide a theoretically grounded mechanism for driving the development of shared understanding. Although the studies highlighted here have started to explore the types of questions most important to developing shared understanding, there has been little research dealing with how these change over the course of the design process. As such, the investigation of how question use changes across different design stages is a key area of further study, but beyond the scope of the current work. Thus the aim of the intervention used in this study is to provide direct communication support for the questioning/feedback cycle, with the dependant variable: shared understanding - examined by comparing team members' mental models. As such, the intervention does not guide the type of questions to be asked; only how they can be framed in order to better support shared understanding development.

Figure 1: Research framework linking team composition and shared understanding development 


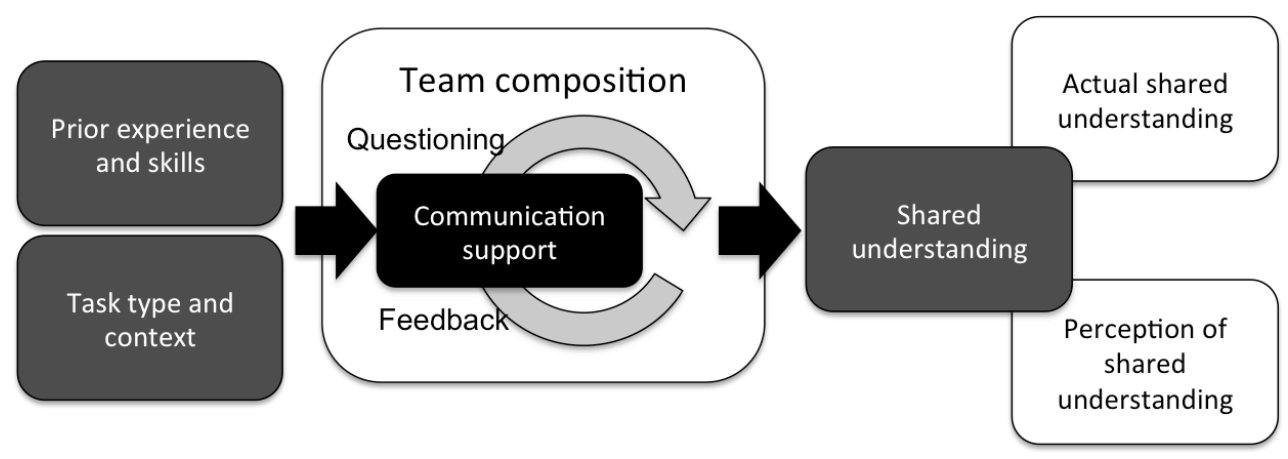

\subsection{Hypotheses: Communication Support and Shared Understanding}

\section{Development in Distributed Teams}

The development of shared understanding in teams is underpinned by effective communication (Ko, Kirsch, and King 2005), where information is transformed into knowledge through a process of structuring, evaluating, and interpreting (Swaab, Postmes, and Neijens 2002). This forms the basis for producing common mental models. Within this process, direct questioning coupled with more discursive exchange plays a key role (Deken et al. 2012). Questions form the core of exchanges that bring together fact and reason (Eris 2002), additional context (Aurisicchio, Bracewell, and Wallace 2010), and varied perspectives. Thus the cycle of question asking, feedback, and negotiation is critical to shortterm shared understanding development (Mulder, Swaak, and Kessels 2004; Mulder, Swaak, and Kessels 2002). This is related to Eris's (2002) characterisation of question asking as 'creative negotiation', where a team develop a shared understanding of the design using shared representations (Qu and Hansen 2008). Here, the transition between understanding and representation is achieved through question asking and negotiation. Linking these concepts to task and team related planning type activities, Lanaj et al. (2012) state that poor feedback i.e. incomplete or unsatisfying answers to questions, results in individuals ignoring the shared operational vision and instead basing decisions on the team members' own individual experience. Thus shared understanding development in teams builds on mechanisms that are general across team types and context as illustrated by Earley and Mosakowski (2000) in their 
observations of long-term shared understanding development. Here, they highlight how the systematic elicitation and evaluation of the views of all team members is a key success factor, which can be generally facilitated through communication support. This leads to the first hypotheses:

H1: All teams (independent of whether they are heterogeneous or homogenous) exposed to question asking training and support will display greater perceived shared understanding, compared to teams without support.

H2: All teams (independent of whether they are heterogeneous or homogenous) exposed to question asking training and support will display greater actual shared understanding, compared to teams without support.

In homogeneous teams Mulder et al. (2004) identify, questioning and feedback together with a number of other concepts, as mediators of short-term shared understanding. Despite the significance of this work and others in the software development context (Levesque, Wilson, and Wholey 2001; Herbsleb 2007) there remains the two key areas for further testing highlighted here. First, research has typically focused on traditional design/development tasks. However, as highlighted by Hansen et al. (2013) and Herbsleb (2007), the main issues associated with distributed design teams propagate from clarification and design planning type tasks. Second, typical samples focus on a single team type, either homogeneous or heterogeneous. In distributed design and collaboration situations, communication support tools must be effective in both homogeneous and heterogeneous teams (Earley and Mosakowski 2000), hence understanding differences between team types is critical. Focusing on planning type tasks and heterogeneous teams increases the level of difficulty in developing shared understanding due to the increased distance between team members mental models (Auh and Menguc 2005), as well as the increased difficulty in mapping and planning for individual role differentiation over time (Levesque, Wilson, and 
Wholey 2001). As such, Hypotheses 3 and 4 propose that heterogeneous teams should benefit to a greater degree than homogeneous teams from support in developing shared understanding.

H3: Heterogeneous teams will perceive a greater improvement in shared understanding than homogeneous teams when given communication support.

H4: Heterogeneous teams exposed to question asking training and support will display greater improvement in actual shared understanding, compared to homogenous teams.

\section{$3 \quad$ Methodology}

In order to compare the development of shared understanding in both heterogeneous and homogeneous teams two quasi-experimental studies were undertaken. Each study focused on a single team type. The impact of communication support on the development of shared understanding was then examined by comparing a treatment and control condition. In all respects other than team composition the two studies were identical.

\subsection{Setup and Task}

The studies were carried out in six phases as illustrated in Figure 2, based on Ariff et al. (2013) who also used a multistage approach. Darker shading is used in Figure 2 to denote phases related specifically to the intervention: Phase $2=$ training and Phase $4=$ use. Throughout, participants were provided with identical computers and offices in order to control external stimuli. The protocol used to script each phase is provided in the appendix. This includes all questionnaires used, as well as the specific task description and concept mapping activities. 
Phase 1: Participants were asked to individually complete background questionnaires. Once complete they were given a short overview of the study task and introduced to the concept mapping and communication tools to be used.

Phase 2: The intervention was introduced to the participants. This consisted of a group training period for both the control and treatment. This prepared the participants for using the intervention in Phase 4 - described further in Section 3.2.

Phase 3: Participants were given the task brief and allowed 20 minutes to individually search for additional information they might need to complete the task (task description below). They were then asked to individually complete the first concept mapping activity.

Phase 4: The teams were given 75 minutes to complete the task via a remote computer interface using Adobe Connect, simulating distributed working. The task length was based on prototyping studies that were used to ensure that there was sufficient time to complete the task but not so much time that teams could address the task exhaustively, forcing teams to prioritise their work. This was particularly important as the task was of limited complexity. At the end of this session the team was asked to hand in their final output, which was a plan for the collaborative product development process to be followed. They were then asked to complete the second concept mapping activity.

Phases 5 and 6: Participants were asked to individually complete post study questionnaires (5) and a written funnelled debrief (6). This final element provided a hypothesis awareness check, as well as offering a place for participants to record other possible confounds.

The overall progression of the study is summarised in Figure 2. The 'barriers' shown in Figure 2 represent the participants being isolated during that phase. In Phase 4 the participants are isolated physically but given access to computer-based communication tools to simulate a distributed work environment. 
Figure 2: Experimental overview

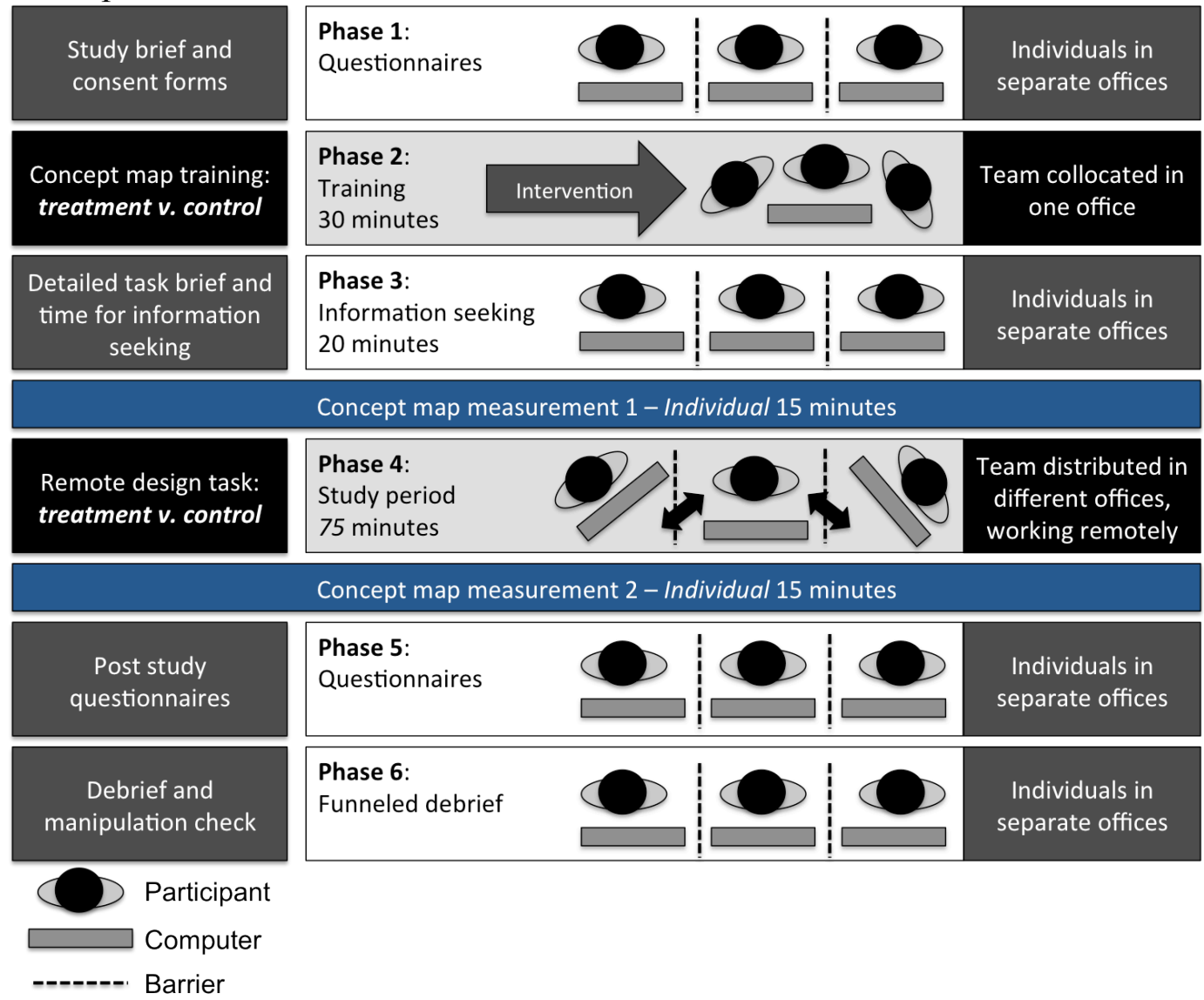

The artificial task was based on the previously validated design task used by Cash et al. (2013). An artificial task was used to eliminate task variables from the experiment (Salas, Cooke, and Rosen 2008; Kirk 2009). The brief was adapted to focus on scoping the product and planning the subsequent design process to be followed. The brief is summarised here but is provided in full in the appendix, which also includes the full experimental protocol: "The idea is to provide a universal camera mount, which can be attached to a range of remotely controlled aerial vehicles. The mount will also give the option for remote orientation, and control of the camera. The overall objective of this meeting is to produce a detailed plan for the collaborative design, and manufacture of the product, maximising the skills of each company."

During Phase 3 participants were randomly allotted information on one of three company profiles to ground their contribution to the team task. This provided each participant 
with different task-related information better reflecting typical distributed engineering design work (Hansen, Zhang, and Ahmed-Kristensen 2013). The company profiles respectively delivered information on aerial vehicles (blimps/balloons specifically), camera mountings, and actuators, and were based on similarly sized real-world companies in order to help improve the realism of the task. These were controlled for word length, tone, and graphic content to avoid systemic bias.

\section{Study 1: Heterogeneous Sample}

In the first study a sample of 42 was used (14 female and 28 male). These formed a highly heterogeneous group, which was randomly allocated to 14 three-person teams. Random allocation was used to reduce systemic biases (Torgerson and Torgerson 2003; Robson 2002).

\section{Study 2: Homogeneous Sample}

In the second study a sample of 36 was used (14 female and 22 male). These formed a highly homogeneous group, which was again randomly allocated to 12 three-person teams.

\section{Study 1 verses Study 2}

Comparing the two samples two main elements differentiate them in terms of team heterogeneity. First, in terms of cultural distribution Study 1 involved substantially more nationalities. At the team level this meant that all teams had a mix of different nationalities with no dominant groups. Further, participants originated from a mix of different educational institutions resulting in two dimensions of cultural diversity (Erez and Gati 2004). In contrast, teams in Study 2 all had at least two members from the same country and all participants originated from the same educational institution and subgroup. Second, in terms of educational background Study 1 had a larger distribution in terms of, education level and focus, and experience level and focus. As such, Study 1 gave substantially higher 
demographic diversity in each team (Miron, Erez, and Naveh 2004). Other widely accepted demographic variables were controlled for in the data analysis (see Section 4.3): age, sex, related experience, and tool/task specific experience (Ang et al. 2007; Miron, Erez, and Naveh 2004). The comparison between samples is summarised in Table 1. In total 78 participants were distributed across 26 teams.

Table 1: Comparison of sample heterogeneity

\begin{tabular}{|c|c|c|}
\hline $\begin{array}{l}\text { Demographic } \\
\text { information }\end{array}$ & $\begin{array}{l}\text { Study 1: Heterogeneous culture and } \\
\text { educational background }\end{array}$ & $\begin{array}{l}\text { Study 2: Homogeneous culture and } \\
\text { educational background }\end{array}$ \\
\hline Team size & 3 & 3 \\
\hline Number & $\begin{array}{l}7 \text { treatment } \mathrm{v} .7 \text { control teams } \\
21 \mathrm{v} .21 \text { participants }\end{array}$ & $\begin{array}{l}6 \text { treatment } \mathrm{v} .6 \text { control teams } \\
18 \text { v. } 18 \text { participants }\end{array}$ \\
\hline Nationality & $\begin{array}{l}\text { All teams had a mix of nationalities } \\
18 \text { countries }\end{array}$ & $\begin{array}{l}\text { All teams had at least two members from one } \\
\text { country } \\
10 \text { countries }\end{array}$ \\
\hline $\begin{array}{l}\text { Educational } \\
\text { background }\end{array}$ & $\begin{array}{l}\text { All teams had a mix of educational } \\
\text { backgrounds in innovation, management, } \\
\text { design, engineering }\end{array}$ & $\begin{array}{l}\text { All teams had a uniform educational } \\
\text { background in design }\end{array}$ \\
\hline Age & Mean $=28 \mathrm{SD}=4.7$ & Mean $=24 \mathrm{SD}=2.2$ \\
\hline Experience & $\begin{array}{l}\text { Mean } 11 \text { months in range of companies (all } \\
\text { teams had a mix of experience areas) }\end{array}$ & $\begin{array}{l}\text { Mean }=10 \text { months in design companies (work } \\
\text { in parallel with education) }\end{array}$ \\
\hline
\end{tabular}

\subsection{Treatment verses Control Intervention}

Two types of intervention were used in each study, a treatment and a control. Both were introduced in Phase 2 via a 20-minute training exercise, and were used in Phase 4 during the design task.

\section{Treatment}

In order to facilitate question asking and feedback during Phase 4, the treatment intervention was split into two elements: training (Phase 2) and use (Phase 4). Training consisted of two parts: a generic part related to the online communication tool (Adobe Connect), and specific part on a question asking protocol. This also included rationale on the importance of question asking and feedback. The training introduced the team to a protocol to be used when a participant identified an important question. The protocol is illustrated in Figure 3 and was initiated using a bell. Hence participants were provided with a common process for answering 
questions, taking decisions, and ensuring group consensus - key elements in developing shared understanding (Spee and Jarzabkowski 2009; Mamykina, Candy, and Edmonds 2002). The protocol asked participants to follow six steps:

1. Alert others to an important question e.g. Person 1 rings bell "how should we manage final assembly?"

2. Repeat question for the team clarifying where necessary e.g. "by final assembly I mean bringing together the subsystems produced by each company and preparing them for distribution."

3. Explicitly gather different perspectives and answers from each team member e.g. Person 2 "I think we should outsource final assembly to a third party" and Person 3 "I think assembly should be at Company 1 's facilities as they are the largest."

4. Elaborate on these answers to establish who is responsible, what they should deliver, when, where, and how it is to be addressed e.g. "so it is Company l's responsibility to set this up, they should deliver an assembly plan to the group by the end of the development phase, and then assembly will take place at their existing facility, and be accommodated by reducing their current product portfolio."

5. Agree on the above information e.g. "are there any objections?"

6. Document the final discussion in the shared workspace e.g. "I have now added these details to the design plan."

Figure 3: The questioning process used as part of the treatment intervention

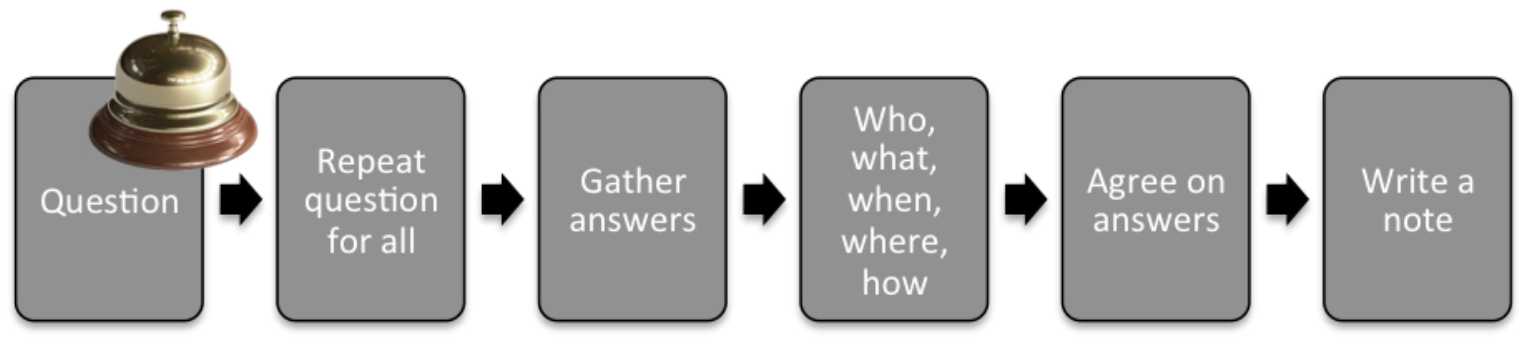

This protocol brings together insights from a number of design works in order to facilitate 
effective conversational question asking, feedback, and conversion towards shared understanding (Dong 2005). Deken et al. (2012) highlight that although direct question asking is not common, knowledge creation through exchange-type discussion is key (respectively accounting for $7 \%$ and $45 \%$ of design meeting time). Thus the protocol encourages diverse discourse around important questions in order to maximise exchange type discussion. Decomposing exchange, Aurisicchio et al. (2010) link questioning activity to the synthesis of information from different perspectives, in a process where people are able to, for example, elaborate context or provide background rationale. The elaboration and discursive elements in the protocol (Steps 3, 4, and 5) provide an explicit framework for exchanging and synthesising differing perspectives. This supports the sharing of information beyond the scope of the initial question (Aurisicchio, Bracewell, and Wallace 2010; Kleinsmann and Valkenburg 2008). In particular, Kleinsmann \& Valkenburg (2008) highlight the importance of managing shared understanding across the interfaces between, for example, different companies or organisational units. Thus the protocol encourages participants to explicitly discuss e.g. who, what, when etc. (Step 4), in order to identify possible interface issues (Oppl and Stary 2013). This brings together both 'fact' and 'reason' type questions to promote creative negotiation (Eris 2002). In order to provide an impetus for the types of discussion and interface issues described by Deken et al. (2012) and Kleinsmann \& Valkenburg (2008) participants were each associated with a specific company profile as described in Section 3.1. Finally, the protocol is designed to conform with the rules laid out by Stenfors et al. (2004): simple to use, flexible, and supporting brokering/idea discussion.

The generic training in Phase 2 was common across both conditions and was used to disguise the introduction of the specific treatment element - ensuring hypothesis blindness and mitigating other experimental biases (Stewart-Williams 2004; Gephart and Antonoplos 1969). 
With the training complete the participants were encouraged to use the protocol for questioning during Phase 4. Thus the questioning protocol was used in conjunction with the Adobe Connect tool. A summary of the protocol was placed alongside participants' monitor within their field of vision. The training and protocol prompt guided questioning without limiting the participants' actions in the task. This allowed the participants to choose what they thought was important enough to ask about and when to use the questioning protocol. In all other respects conversation was unconstrained.

\section{Control}

The control intervention was based on placebo control logic i.e. it should be indistinguishable (to the participant) from the treatment intervention (Adair, Sharpe, and Huynh 1989). In this case the active element was the questioning protocol. As such, the control condition consisted of a similarly staged 20 minute training exercise focused on the generic communication tool to be used by the team. In this way no additional information was introduced by the control training but facilitator interaction and apparent attention were kept the same across all participants, reducing potential bias (Gephart and Antonoplos 1969; Cash and Culley 2014).

\subsection{Measurement}

With respect to the research framework (Figure 1) the intervention was a communication support tool, while the two study groups were designed to have different team compositions. Thus measurement focused on the dependant variable: shared understanding.

\section{Change in Perception of Shared Understanding}

In the context of assessing perception of shared understanding development, previous studies have validated the use of 7-point Likert scale questionnaires (Preston, Karahanna, and Rowe 2006; Badke-Schaub et al. 2007). These questions address several different aspects of shared 
understanding perception, which are internally consistent and can be grouped to give an overall assessment. The different assessment elements are outlined in Table 2 together with relevant studies where similar measures have been used. A control measure was also used to check the quality of the knowledge sharing in the teams, after Chiu et al. (2006). All questions were delivered in a random ordering and assigned positive/negative phrasings to mitigate structural biases (Robson 2002). The full question list is provided as part of the appendix.

Table 2: Shared understanding perception measures

\begin{tabular}{|c|c|}
\hline Measure & Assessment elements \\
\hline Shared understanding & $\begin{array}{l}\text { The problem definition and requirements and how these are shared across the team } \\
\text { (Mulder, Swaak, and Kessels 2004; Badke-Schaub et al. 2007) }\end{array}$ \\
\hline Shared vision & $\begin{array}{l}\text { The aim and scope of the proposed plan as well as the overall timeline (Badke-Schaub } \\
\text { et al. 2007; Chiu, Hsu, and Wang 2006) }\end{array}$ \\
\hline Solution understanding & $\begin{array}{l}\text { The details of the proposed plan and how it will be executed by the team (Preston, } \\
\text { Karahanna, and Rowe 2006) }\end{array}$ \\
\hline $\begin{array}{l}\text { Role distribution } \\
\text { understanding }\end{array}$ & $\begin{array}{l}\text { The participants role in relation to the other team members and the proposed design } \\
\text { process (Preston, Karahanna, and Rowe 2006; Badke-Schaub et al. 2007) }\end{array}$ \\
\hline $\begin{array}{l}\text { Critical issue } \\
\text { understanding }\end{array}$ & The scope, nature, and importance of identified design issues (Ahmed 2005) \\
\hline \multicolumn{2}{|l|}{ Control measure } \\
\hline Knowledge quality & $\begin{array}{l}\text { The relevance and ease of understanding of the information from other participants } \\
\text { (Chiu, Hsu, and Wang 2006) }\end{array}$ \\
\hline
\end{tabular}

\section{Change in Actual Shared Understanding}

Constructed Shared Mental Models (CSMM) give a systematic means for assessing the development of actual shared understanding by comparing different individuals' concept maps (Johnson et al. 2007; O'Connor 2004; Johnson and O'Connor 2008). Concept maps have previously been used in the design context by Badke-Schaub et al. (2007). In this study, participants made an individual concept map representing their understanding of the design plan to be undertaken before and after Phase 4 (see Figure 2). A list of inspirational concepts was provided to support the participants. This list was synthesised from the fundamental design concepts described by Ahmed (2005), Ahmed and Storga (2009), and Badke-Schaub et al. (2007). The list made the task semi-constrained in line with previous studies (Johnson and O'Connor 2008). A semi-constrained design is relevant where participants might not be previously familiar with CSMM's, as in this study (Johnson and O'Connor 2008). Sharedness 
was then assessed with regard to five standard measures of similarity between the individuals' concept maps, summarised in Table 3 and Figure 4. This produced a score for both rounds of mapping (at the end of Phases 3 and 4). Before and after scores could be compared at the team level to assess change in shared understanding. In addition, the total number of concepts used by the participants was considered as an indicator of focus and allowed for a check between teams. For example, a team who wrote many more concepts might accidently generate a higher alignment score if the number of concepts used is not taken into account. This approach was selected over other quantitative alternatives, such as Pathfinder network analysis (Cross, Morris, and Gore 2002), because it includes the additional components of sequence, important terms and concepts, and reciprocal or directional relationships between concepts (Johnson and O'Connor 2008; Novak and Cañas 2008). In particular, the scoring of important terms (' 4 in Figure 4), and the directionality of relationships between concepts (' 3 in Figure 4) contributed significantly to the sharedness results (Section 4).

Figure 4: Measures for shared mental models using concept maps

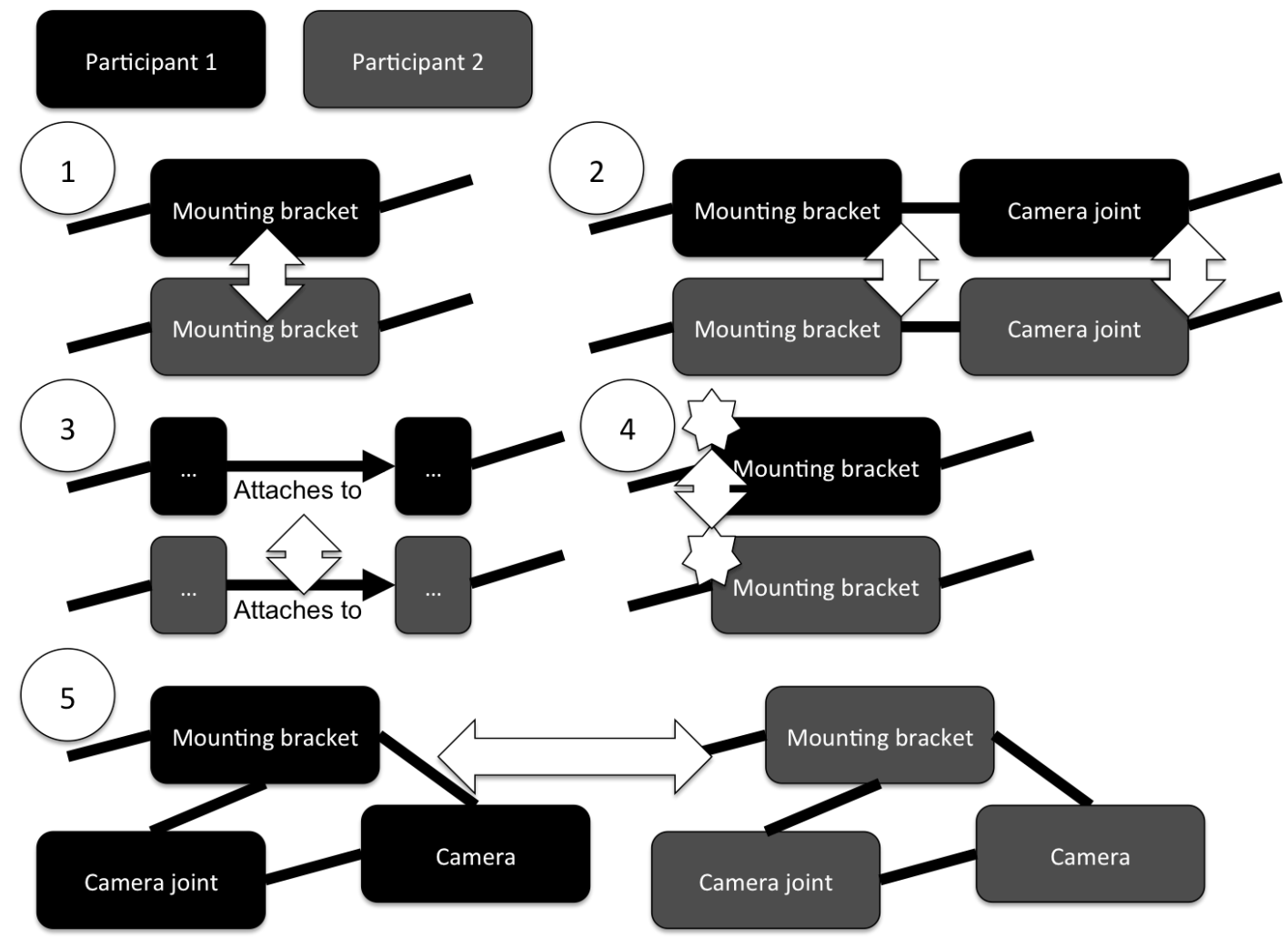


Table 3: CSMM development measures

\begin{tabular}{|l|l|}
\hline Measure & Assessment elements \\
\hline 1. Shared concepts & Concepts with a common label \\
\hline 2. Shared sequences & Strings of concepts with a common ordering \\
\hline 3. Shared links & Two (or more) concepts with a common label and a common link between them \\
\hline 4. Shared importance & Concepts with a common priority indication \\
\hline 5. Shared clusters & Clusters of concepts with common labels and common links \\
\hline Additional measure & \\
\hline Number of concepts & The total number of concepts used by the team and each individual \\
\hline
\end{tabular}

\section{Overall Design Performance}

Finally, design performance was assessed as a control measure using the final design plan produced by each team, recorded on a single sheet of A3 paper at the end of Phase 4. In this context, performance provided an ideal control measure as shared understanding is not directly associated with immediate performance gains, instead manifesting in performance improvement over time (Hult, Ketchen, and Slater 2004). Performance provides a means of controlling variability in teams' based line design ability. There are few accepted research guidelines for assessing the quality of design plans. As such, a manifest concept-based approach was used in line with the shared understanding assessment. The key metric was the number and range of concepts articulated in the plan - here referred to as 'elements' for clarity. This manifest assessment of plan elements supports alignment with the CSMM metric as both are concept based, and provides a quantitative basis for controlling variation in ability. However, for more extensive qualitative discussion of design plan quality it would be necessary to employ some form of expert rating.

The design plan required the team to bring together their thoughts and synthesise one agreed document. The plan was assessed by counting the number of elements linked to the performance measures outlined in Table 4 and identified in the same manner as in the concept map rating. These areas were defined based on the works of Ahmed (2005), Ahmed and Storga (2009), who provide ontologies describing engineering design activities. An overall score was then calculated to compare the plan documents. The results were again normalised 
against the total number of listed elements, to produce a percentage, in order to account for differences in writing speed.

Table 4: Design performance measures

\begin{tabular}{|l|l|}
\hline Measure & Assessment elements \\
\hline Design process & $\begin{array}{l}\text { Task identification, design issues, task distribution, manufacturing plan, distribution } \\
\text { plan }\end{array}$ \\
\hline Physical product & $\begin{array}{l}\text { Component, subassembly, and assembly identification, interfaces, structure and form, } \\
\text { manufacturing methods, links to product families }\end{array}$ \\
\hline Functions & Functions, plan for lifecycle \\
\hline Design issues & $\begin{array}{l}\text { Identification of critical considerations when completing the design process, critical } \\
\text { relationships, key decision gates, potential issues preventing completion }\end{array}$ \\
\hline
\end{tabular}

\subsection{Coding and Analysis}

All documents produced during the study (questionnaires, concept maps, and final design plans) were transcribed as a basis for analysis. A manifest approach (direct comparison of the text without intermediary interpretation) was used throughout the coding and analysis in order to minimise bias (Cash and Snider 2014). For example, when comparing concepts on the participants' concept maps the wording was required to be the same in order to code them as analogous. Where different wordings were used it was assumed that different concepts were being referenced e.g. 'task ordering' and 'task allocation' were coded as different concepts. Although it is possible that some shared concepts might be missed using this approach this only makes the study more, rather than less, robust. Further, it affects all teams to the same degree and since increase in shared understanding is the primary measure this will not affect the final results. For the final design plan the coding followed a similar manifest approach with elements being counted based on their worded description only.

In order to code the concept map and design plan results, all documents were anonymised and randomly ordered before being coded by two independent researchers with design experience. Anonymization and random ordering was used to reduce systematic bias in the rating and ensure rater hypothesis blindness. Due to the manifest approach facilitated by the concept maps, initial inter-coder agreement was over 95\%. All remaining disagreements 
were then resolved before continuing with the analysis. The high level of agreement between the independent evaluations of the concept maps supports the robustness of the approach in this context. The same approach was then used for the design plan assessment. Here, initial inter-rater agreement was 96\%. Again disagreements were resolved before analysis.

\section{$4 \quad$ Results}

This section outlines the results for the two studies. Throughout, the results have been tested using one-tailed statistical tests due to the directionality of the hypotheses and prior theory as outlined in Section 2.

\subsection{Perception of Shared Understanding}

Perception of shared understanding was measured via the Likert questionnaires (Phase 5, Figure 2) outlined in Table 2 at the individual level ( $\mathrm{n}=21$ heterogeneous/18 homogeneous). Seventeen questions were distributed across the measures in Table 2, while six questions related to the control measure. A Cronbach alpha test was used to check for consistency in the question groupings. This showed all groupings to be appropriate (alpha $>0.75$ in all conditions) (Cortina 1993).

The results and significance values for each study and condition are reported in Table 5. Two statistical tests were used to compare the difference between the treatment and control means for robustness. The first was a one tailed students t-test for populations with different variance (Walker 2010). The second was a one tailed Mann-Whitney U test, which is used for ordinal Likert scales (Walker 2010). 
Table 5: Perception of shared understanding

\begin{tabular}{|c|c|c|c|}
\hline \multicolumn{4}{|c|}{ Overall results } \\
\hline & \multicolumn{2}{|c|}{ Mean response for all questions } & \multirow{2}{*}{\begin{tabular}{|l|} 
Difference \\
T-test \\
Mann-Whitney U
\end{tabular}} \\
\hline $\begin{array}{l}\text { Overall perception of shared } \\
\text { understanding }\end{array}$ & Treatment & Control & \\
\hline Heterogeneous $(\mathrm{n}=21)$ & 4.67 & 4.85 & $\begin{array}{l}p=0.252 \\
p=0.278\end{array}$ \\
\hline Homogeneous $(n=18)$ & 4.84 & 4.89 & $\begin{array}{l}p=0.407 \\
p=0.242\end{array}$ \\
\hline \multicolumn{4}{|c|}{ Results by individual measure (heterogeneous/homogeneous) } \\
\hline Measure & Treatment & Control & $\begin{array}{l}\text { T-test } \\
\text { Mann-Whitney U }\end{array}$ \\
\hline Shared understanding & $5.23 / 4.75$ & $5.48 / \mathbf{5 . 4 2}$ & $\begin{array}{l}p=0.183 / \mathbf{0 . 0 3 1} \\
p=0.242 / \mathbf{0 . 0 7 1}\end{array}$ \\
\hline Shared vision & $4.69 / 4.80$ & $5.08 / 5.21$ & $\begin{array}{l}p=0.111 / 0.463 \\
p=0.145 / 0.448\end{array}$ \\
\hline Solution understanding & $4.38 / 4.61$ & $4.48 / 4.73$ & $\begin{array}{l}p=0.402 / 0.416 \\
p=0.480 / 0.390\end{array}$ \\
\hline Role distribution understanding & $4.77 / 4.90$ & $4.91 / 4.79$ & $\begin{array}{l}p=0.340 / 0.352 \\
p=0.337 / 0.230\end{array}$ \\
\hline Critical issue understanding & $4.14 / 4.13$ & $4.02 / 4.50$ & $\begin{array}{l}p=0.323 / 0.178 \\
p=0.351 / 0.206\end{array}$ \\
\hline
\end{tabular}

Here homogeneous teams showed a significantly higher perception of shared understanding in the control condition. This highlights a key difference in how the two team types reacted to the questioning support intervention. Combining the findings for both team types further highlighted the trend towards higher perception of shared understanding in the control condition: combined treatment (5.09), combined control (5.49), $p=0.024$ (t-test), $p=0.059$ (Mann-Whitney U).

\subsection{Actual Shared Understanding}

Actual sharedness was measured at both the team and individual level (team level $\mathrm{n}=7$ heterogeneous/6 homogeneous). Two overall measures were used as outlined in Table 3: the increase in the sharedness score between the first and second concept mapping exercise, and the decrease in the number of concepts used in the same period. These were normalised against the overall number of concepts used by each team in order to account for writing speed. Significance was tested using a one tailed students t-test for populations with different 
variance (Walker 2010), and the findings are recorded in Table 6.

At the individual level $(n=21 / 18)$ the percentage change in the number of shared concepts was evaluated are shown in Table 6 (i.e. the number of shared concepts/the total concepts listed by the participant). A one tailed students t-test was used, but for within populations (Walker 2010). The use of a within population test was appropriate here due to the focus on the difference between the first and second concept mapping exercise for each participant.

Table 6: Team and individual shared understanding

\begin{tabular}{|c|c|c|}
\hline & \multicolumn{2}{|c|}{ Team level } \\
\hline & \multicolumn{2}{|c|}{$\begin{array}{c}\text { Mean change in sharedness between Phases } 3 \\
\text { and } 4\end{array}$} \\
\hline Condition / measure & Treatment & Control \\
\hline Heterogeneous $(n=7) /$ number of concepts & $\begin{array}{l}-10.34 \% \\
p=0.061\end{array}$ & $\begin{array}{l}1.15 \% \\
p=0.378\end{array}$ \\
\hline Heterogeneous $(n=7) /$ sharedness score & $\begin{array}{l}26.24 \% \\
p=0.028\end{array}$ & $\begin{array}{l}-0.35 \% \\
p=0.425\end{array}$ \\
\hline Homogeneous $(n=6) /$ number of concepts & $\begin{array}{l}-2.37 \% \\
p=0.349\end{array}$ & $\begin{array}{l}-0.87 \% \\
p=0.422\end{array}$ \\
\hline \multirow[t]{3}{*}{ Homogeneous $(n=6) /$ sharedness score } & $\begin{array}{l}21.58 \% \\
p=0.037\end{array}$ & $\begin{array}{l}5.53 \% \\
p=0.202\end{array}$ \\
\hline & \multicolumn{2}{|c|}{ Individual level } \\
\hline & \multicolumn{2}{|c|}{\begin{tabular}{|} 
Mean change in shared concepts between Phases \\
3 and 4 \\
\end{tabular}} \\
\hline Condition & Treatment & Control \\
\hline Heterogeneous $(\mathrm{n}=21)$ & $\begin{array}{l}18.11 \% \\
p=0.001\end{array}$ & $\begin{array}{l}-1.76 \% \\
p=0.365\end{array}$ \\
\hline Homogeneous $(\mathrm{n}=18)$ & $\begin{array}{l}18.44 \% \\
p=0.001\end{array}$ & $\begin{array}{l}-0.54 \% \\
p=0.449\end{array}$ \\
\hline
\end{tabular}

At both the individual and team levels all results trended towards a significant improvement in the treatment condition. This indicates a fundamental similarity between the team types: questioning support substantially increases shared understanding. The results for the combined sample (i.e. all treatment teams verses all control teams) are outlined in Table 7. 
Table 7: Team and individual shared understanding for all participants

\begin{tabular}{|c|c|c|}
\hline & \multicolumn{2}{|c|}{ Team level } \\
\hline & \multicolumn{2}{|c|}{$\begin{array}{c}\text { Mean change in sharedness between Phases } 3 \\
\text { and } 4\end{array}$} \\
\hline Condition / measure & Treatment & Control \\
\hline All $(n=13) /$ number of concepts & $\begin{array}{l}-6.66 \% \\
p=0.061\end{array}$ & $\begin{array}{l}0.22 \% \\
p=0.442\end{array}$ \\
\hline \multirow[t]{3}{*}{ All $(n=13) /$ sharedness score } & $\begin{array}{l}24.09 \% \\
p=0.003\end{array}$ & $\begin{array}{l}2.36 \% \\
p=0.291\end{array}$ \\
\hline & \multicolumn{2}{|c|}{ Individual level } \\
\hline & \multicolumn{2}{|c|}{$\begin{array}{l}\text { Mean change in shared concepts between Phases } \\
3 \text { and } 4\end{array}$} \\
\hline Condition & Treatment & Control \\
\hline All $(\mathrm{n}=39)$ & $\begin{array}{l}18.27 \% \\
p<0.001\end{array}$ & $\begin{array}{l}-1.19 \% \\
p=0.358\end{array}$ \\
\hline
\end{tabular}

\subsection{Control Variables}

None of the check variables showed a significant difference across the conditions (task specific experience, expectation, background information, baseline variables, knowledge quality, and perception of own performance). In particular knowledge quality showed no significant difference across the conditions (Cronbach alpha: 0.79 for the treatment and 0.73 for the control (Cortina 1993)). This is further supported by baseline comparisons of the number of concepts produced or shared by the two team types. The hypothesis awareness check also found no awareness of the study condition or hypotheses. Overall this supports the findings and validity of the study.

Finally design performance was measured at the team level $(n=7 / 6)$ using the factors outlined in Table 4 (based on the final design plan produced at the end of Phase 4, Figure 2). The results for design performance are summarised in Table 8. A one tailed students t-test for populations with different variance was again used in this case (Walker 2010). These findings suggest a similar response from both treatment and control, with no significant differences identified. This again supports the robustness of the shared understanding results by allowing baselined ability to be controlled. As such, this result is in line with previous research and is expected within the context of the study. 
Table 8: Design performance

\begin{tabular}{|c|c|c|c|}
\hline \multicolumn{4}{|c|}{ Overall results } \\
\hline & \multicolumn{2}{|c|}{ Mean response for all questions } & Difference \\
\hline Overall design performance & Treatment & Control & T-test \\
\hline Heterogeneous $(\mathrm{n}=7)$ & 21.43 & 19.57 & $p=0.392$ \\
\hline Homogeneous $(n=6)$ & 19.67 & 22.33 & $p=0.278$ \\
\hline \multicolumn{4}{|c|}{ Results by individual measure (heterogeneous/homogeneous) } \\
\hline Measure & Treatment & Control & T-test \\
\hline Design process & $13.71 / 14.33$ & $12.29 / 17.17$ & $p=0.393 / 0.262$ \\
\hline Physical product & $2.86 / 1.83$ & $5.14 / 3.00$ & $p=0.081 / 0.106$ \\
\hline Functions & $0.43 / 0.17$ & $0.43 / 0.17$ & $p=0.500 / 0.500$ \\
\hline Issues & $4.43 / 3.33$ & $1.71 / 2.00$ & $p=0.079 / 0.195$ \\
\hline
\end{tabular}

\subsection{Overall Alignment between the Team Types}

Table 9 shows a summary of the overall results for the two team types, bringing together the results for comparison. This aims to highlight areas of agreement/disagreement between the results from the two studies, and the key insights that can be drawn from this comparison. Here, alignment is used to describe the degree to which results are similar in terms of directionality and extent.

Table 9: Overall comparison of alignment between the two team types

\begin{tabular}{|c|c|c|}
\hline & Heterogeneous & Homogeneous \\
\hline $\begin{array}{l}\text { Perception of change in } \\
\text { shared understanding }\end{array}$ & $\begin{array}{l}\text { Overall no difference in perception of } \\
\text { improvement across conditions } \\
\text { i.e. neither condition perceived a } \\
\text { significant improvement }\end{array}$ & $\begin{array}{l}\text { Overall more positive perception of } \\
\text { improvement in shared understanding by } \\
\text { the control team } \\
\text { i.e. the intervention was not perceived to } \\
\text { have had a positive effect }\end{array}$ \\
\hline Comparison & \multicolumn{2}{|c|}{$\begin{array}{l}\text { - There was a substantial difference between the two team types } \\
\text { - Perception and actual improvement were not aligned in the homogeneous teams } \\
\text { Not aligned in directionality or extent }\end{array}$} \\
\hline $\begin{array}{l}\text { Actual change in shared } \\
\text { understanding }\end{array}$ & $\begin{array}{l}\text { Overall significantly greater improvement } \\
\text { in shared understanding by the treatment } \\
\text { team } \\
\text { i.e. the intervention had a positive effect }\end{array}$ & $\begin{array}{l}\text { Overall significantly greater improvement } \\
\text { in shared understanding by the treatment } \\
\text { team } \\
\text { i.e. the intervention had a positive effect }\end{array}$ \\
\hline rison & \multicolumn{2}{|c|}{$\begin{array}{l}\text { - Both team types show a significant positive effect from the intervention } \\
\text { - The team level effect is substantially larger in the heterogeneous teams } \\
\text { Aligned in directionality but to a lesser degree extent }\end{array}$} \\
\hline
\end{tabular}

\section{Discussion}

Based on the results described above the four hypotheses defined in Section 2 can be answered as follows: 
H1: All teams exposed to question asking training and support will display greater perceived shared understanding, compared to teams without support: Not supported

H2: All teams exposed to question asking training and support will display greater actual shared understanding, compared to teams without support: Supported

H3: Heterogeneous teams will perceive a greater improvement in shared understanding than homogeneous teams when given communication support: Supported

H4: Heterogeneous teams exposed to question asking training and support will display greater improvement in actual shared understanding, compared to homogenous teams: Supported

With respect to perception of improvement (H1 \& H3) there are substantial differences in the reaction of the two team types, with no difference in perception in the heterogeneous study and a significant negative trend in the homogeneous study. This is despite both studies showing significant actual improvement in shared understanding due to the intervention. This contrast in perceived versus actual improvement reinforces the importance of this type of comparison, as highlighted by Johnson et al. (2007). This finding poses a substantial problem for the development of communication support tools that aim to effectively support all team types. In particular, there is a need to align the perception of improvement with the reality of improvement if teams are to accept tools.

With respect to actual shared understanding (H2 \& H4) both studies showed a significant improvement in shared understanding when using the support tool (Table 6). The treatment effect was consistently positive across all measures for both team types, although it was substantially more pronounced in the heterogeneous context - in line with previous research on design teams (Eris, Martelaro, and Badke-Schaub 2014). This is interesting because the homogeneous teams were not significantly more aligned pre-test than the heterogeneous teams (based on the first concept mapping task after Phase 3). Further, no 
difference in baseline ability was found based on the design performance and other check measures. This points to the need for further research on the specific behaviours associated with the two team types, and their effect on subsequent development of shared understanding. This also raises the question of what aspects of heterogeneity contribute most to these differences and thus how team formation can be more effectively managed. This is closely linked to work on team cohesion and trust (Panteli and Sockalingam 2005), and thus to communication behaviour and awareness of each individual team member's needs (Lawson et al. 2009).

A final element that can be derived from this work is methodological. The manifest analysis of shared understanding using CSMM's (Johnson and O'Connor 2008) proved an effective measurement tool in the context of the design team. The concept maps required only ten minutes to complete and lend themselves to automated analysis. Further, by minimising interpretation of the map contents high inter-rater agreement was achieved with only minimal training (Section 3). However, it is important to note that this primarily applies to more static shared constructs, such as, organisational structures, task allocation, time plans, and foundational assumptions, some of which are addressed by Kleinsmann \& Valkenburg (2008). However, much of design work is also concerned with the evolving design concept, which is not addressed by this type of approach. In this evolving context shared understanding is an emergent phenomena where concept maps are unsuitable (Dong, Kleinsmann, and Deken 2013; Dong 2005). However, their utility in the context of this study suggests they are an effective complementary approach suitable for application to many aspects of design work. Together these findings have a number of implications for practice and research, as well as some specific limitations, addressed in the following sections.

\subsection{Implications}

First, this work reinforces the importance of shared understanding and team communication 
support in planning type tasks common to distributed engineering design teams. Both team types showed improvement of actual shared understanding. This highlights the utility of semistructured question asking and feedback on the short-term development of shared understanding, a critical factor in longer term project performance as described by Hult et al. (2004).

Second, the difference in perception experienced by the two team types, and the overall lack of positive perception of the intervention highlights the need for careful implementation and iteration when deploying communication support tools. As such, further work is needed to better understand what approach could be used to align perception and reality to ensure acceptance and adoption of communication support tools even in homogeneous teams.

Third, this work feeds into the wider literature on team behaviour in the distributed engineering design context and points to the possible utility of small interventions having a significant impact on team shared understanding via their integration with everyday tasks. In particular, there is scope for exploring the use of questioning support in other engineering design situations in line with other work in this domain (Ariff, Eris, and Badke-Schaub 2013).

\subsection{Limitations}

The main limitation of this work is the sample size: 78 participants in 26 teams. Although this limits the statistical power of the findings it is mitigated by the use of multiple measures, and the alignment across measures. Further, many of the measure groups do give significant results, and the sample size is appropriate given the research aims. As such, it is possible to consider the results as significant. Further, the use of checks throughout the study, including pre- and post-test baselines reduces the likelihood of systematic bias and further support validity. Finally, the results confirm the logic outlined in the research framework with few deviant cases. 
Second, the study focuses on shared understanding development and questioning support in the context of a specific task. This means that design performance is not directly influenced in the short term - as born out in the results. However, shared understanding is strongly linked to long-term performance improvement (Hult, Ketchen, and Slater 2004). As such, shared understanding measurement in the short-term is appropriate in this case, given the focus on specific tasks encountered by distributed engineering design teams.

\section{Conclusions}

This paper reports on two quasi-experimental studies examining the development of shared understanding in heterogeneous and homogeneous distributed engineering design teams using question-asking support.

The findings from both studies highlight the importance of questioning support for distributed engineering design teams of all levels of heterogeneity. The results reported here point to a new perspective on question-asking activity as a key facilitator of shared understanding development. This links to the longer term development of shared understanding via the works of Mulder et al. (2004) and Hult et al. (2004), who both highlight its importance in overall project performance.

A second key conclusion is that despite the relatively minimal intervention and short study duration, homogeneous teams did not perceive any improvement in shared understanding - indeed reacting negatively to the intervention. This is despite a significant actual improvement in shared understanding. This points to the value of implementing communication support tools as well as the need to ensure that teams accept the support by making improvements visible. In particular, further work is needed to explore how communication support tools should be incorporated in practice to better align perceived and actual improvement. 
Finally, the alignment between the various measures used and the practical utility of the concept mapping approach, points to this method as useful and applicable when considering understanding related to more static aspects of design work, such as plans (Dong, Kleinsmann, and Deken 2013). This approach requires further study in the design context but complements existing works in this direction by e.g. Ariff et al. (2013) and Badke-Schaub et al. (2007).

Based on these conclusions two main areas of further work emerge. First, examining other design populations and situations. Specifically, the exploration of shared understanding across a more systematically varied range of team types might allow further decomposition of the various heterogeneity effects and improved support in this context. This would extend understanding of how communication tools can be developed and deployed successfully. Second, there is a need to expand the scope and depth of situations covered and the time frame considered in order to better link: works in engineering design (typically focused on specific tasks); and wider research on shared understanding (typically at the project level). In particular, studies such as that by Deken et al. (2012) have started to identify the types of questions that are most important to developing shared understanding in design but there has been little research dealing with how this changes over the course of the design process. This is coupled with the need to understand how short term improvements in performance translate into long term improvements at the project level.

\section{References}

Adair, J G, D Sharpe, and C L Huynh. 1989. "Placebo, Hawthorne, and Other Artifact Controls: Researchers' Opinions and Practices." JOUR. The Journal of Experimental Education 57 (4): 341-55. http://www.jstor.org/stable/20151783.

Ahmed, S. 2005. "Encouraging Reuse of Design Knowledge: A Method to Index Knowledge." JOUR. Design Studies 26 (6): 565-92.

Ahmed, S, and M Storga. 2009. "Merged Ontology for Engineering Design: Contrasting Empirical and Theoretical Approaches to Develop Engineering Ontologies.” JOUR. AI 
EDAM (Artificial Intelligence for Engineering Design, Analysis and Manufacturing) 23 (4): 391-407.

Ahmed, S, K M Wallace, and L T M Blessing. 2003. "Understanding the Differences between How Novice and Experienced Designers Approach Design Tasks.” JOUR. Research in Engineering Design 14 (1): 1-11.

Ang, S, and A C Inkpen. 2008. "Cultural Intelligence and Offshore Outsourcing Success: A Framework of Firm-Level Intercultural Capability." JOUR. Decision Sciences 39 (3): 337-58.

Ang, S, L Van Dyne, C Koh, K Y Ng, K J Templer, C Tay, and N A Chandrasekar. 2007. "Cultural Intelligence: Its Measurement and Effects on Cultural Judgment and Decision Making, Cultural Adaptation and Task Performance." JOUR. Management and Organization Review 3 (3). Wiley Online Library: 335-71.

Ariff, N S N A, O Eris, and P Badke-Schaub. 2013. "How Designers Express Agreement.” In 5th IASDR Conference, 1-10. Tokyo, Japan. http://repository.tudelft.nl/assets/uuid:64604893-ce58-4db5-b716ea2b6e01d788/298529.pdf.

Auh, Seigyoung, and Bulent Menguc. 2005. "Top Management Team Diversity and Innovativeness: The Moderating Role of Interfunctional Coordination." Industrial Marketing Management 34 (3): 249-61. doi:10.1016/j.indmarman.2004.09.005.

Aurisicchio, M, S Ahmed, and K Wallace. 2007. "Questions as a Tool to Design." In ASME Conference on Design Theory and Methodology. Las Vegas, USA. http://www.dtu.dk/English/Service/Phonebook.aspx?lg=showcommon\&id=208683.

Aurisicchio, M, R Bracewell, and K Wallace. 2006. "Evaluation of DRed a Way of Capturing and Structuring Engineering Design Processes.” In NordDesign. Reykjavik, Iceland.

. 2010. "Understanding How the Information Requests of Aerospace Engineering Designers Influence Information-Seeking Behaviour." JOUR. Journal of Engineering Design 21 (6): 707-30. doi:10.1080/09544820902877583.

Badke-Schaub, P, K Lauche, A Neumann, and S Ahmed. 2007. "Task - Team - Process: Assessment and Analysis of the Development of Shared Representations in an Engineering Team.” In Design Thinking Research Symposium, 1-12. London, UK.

Barkema, H G, and O Shvyrkov. 2007. "Does Top Management Team Diversity Promote or Hamper Foreign Expansion?" Strategic Management Journal 28 (7): 663-80. doi:10.1002/smj.

Bittner, E A C, and J M Leimeister. 2013. "Why Shared Understanding Matters - Engineering a Collaboration Process for Shared Understanding to Improve Collaboration Effectiveness in Heterogeneous Teams." In 2013 46th Hawaii International Conference on System Sciences, 106-14. Maui, Hawaii, USA: Ieee. doi:10.1109/HICSS.2013.608.

Carpenter, Mason A, and W Fredrickson, J. 2001. "Top Managment Teams, Global Strategic Posture and the Moderating Role of Uncertainty." Academy of Management Journal 44 (3): $533-46$.

Carson, J B, P E Tesluk, and J A Marrone. 2007. "Shared Leadership in Teams: An Investigation of Antecedent Conditions and Performance." Academy of Management Journal 50 (5): 1217-34. doi:10.2307/20159921.

Cash, P, and S Culley. 2014. "The Role of Experimental Studies in Design Research." In The Routledge Companion to Design Research, edited by P Rodgers and J Yee, 175-89. 
Routledge.

Cash, P, B Hicks, S Culley, and T Adlam. 2015. "A Foundational Observation Method for Studying Design Situations." Journal of Engineering Design 26 (7-9): 187-219. doi:10.1080/09544828.2015.1020418.

Cash, P, B J Hicks, and S J Culley. 2013. "A Comparison of Designer Activity Using Core Design Situations in the Laboratory and Practice." JOUR. Design Studies 34 (5): 575611. doi:http://dx.doi.org/10.1016/j.destud.2013.03.002.

Cash, P, and C Snider. 2014. "Investigating Design: A Comparison of Manifest and Latent $\begin{array}{lccc}\text { Approaches." Design } & \text { Studies } & 35 & \text { (5): } \\ \text { http://www.sciencedirect.com/science/article/pii/S0142694X14000295. }\end{array}$

Chatman, J A, and F J Flynn. 2001. "The Influence of Demographic Heterogeneity on the Emergence and Consequences of Cooperative Norms in Work Teams." Academy of Management Journal 44 (5): 956-74.

Chiu, C-M, M-H Hsu, and E T G Wang. 2006. "Understanding Knowledge Sharing in Virtual Communities: An Integration of Social Capital and Social Cognitive Theories." Decision Support Systems 42 (3): 1872-88. doi:10.1016/j.dss.2006.04.001.

Cortina, J M. 1993. "What Is Coefficient Alpha? An Examination of Theory and Applications." Journal of Applied Psychology 78 (1): 98-104. http://psycnet.apa.org/journals/apl/78/1/98/.

Cross, S E, M L Morris, and J S Gore. 2002. "Thinking about Oneself and Others: The Relational-Interdependent Self-Construal and Social Cognition." Journal of Personality and Social Psychology 82 (3): 399-418. doi:10.1037/0022-3514.82.3.399.

Dahlin, Kristina B, Laurie R Weingart, and Pamela J Hinds. 2005. "Team Diversity and Information Use." Academy of Management Journal 48 (6): 1107-23. doi:10.5465/AMJ.2005.19573112.

DeFranco, J F, C J Neill, and R B Clariana. 2011. "A Cognitive Collaborative Model To Improve Performance in Engineering Teams - A Study of Team Outcomes and Mental Model Sharing." Systems Engineering 14 (3): 305-26. doi:10.1002/sys.

Deken, F, M Kleinsmann, M Aurisicchio, K Lauche, and R Bracewell. 2012. "Tapping into Past Design Experiences: Knowledge Sharing and Creation during Novice-Expert Design Consultations." Research in Engineering Design 23 (3): 203-18. doi:10.1007/s00163-011-0123-8.

Dong, Andy. 2005. "The Latent Semantic Approach to Studying Design Team Communication." JOUR. Design Studies $26 \quad$ (5): 445-61. doi:10.1016/j.destud.2004.10.003.

Dong, Andy, Maaike S Kleinsmann, and Fleur Deken. 2013. "Investigating Design Cognition in the Construction and Enactment of Team Mental Models." JOUR. Design Studies 34 (1): 1-33. doi:10.1016/j.destud.2012.05.003.

Dym, C L, A M Agogino, O Eris, D D Frey, and L Leifer. 2005. "Engineering Design Thinking, Teaching, and Learning." JOUR. Journal of Engineering Education 94 (1): 103-20.

http://sfxhosted.exlibrisgroup.com/bath?sid=google\&auinit=CL\&aulast=Dym\&atitle=En gineering design thinking, teaching, and learning\&title $=$ IEEE engineering management review $\&$ volume $=34 \&$ issue $=1 \&$ date $=2006 \&$ spage $=65 \&$ issn $=0360-8581$.

Earley, P C, and E Mosakowski. 2000. "Creating Hybrid Team Cultures: An Empirical Test 
of Transnational Team Functioning." Academy of Management Journal 43 (1): 26-49.

Erez, M, and E Gati. 2004. "A Dynamic, Multi-Level Model of Culture: From the Micro Level of the Individual to the Macro Level of a Global Culture." JOUR. Applied Psychology 53 (4): 583-98.

Eris, O. 2002. "Perceiving, Comprehending and Measuring Design Activity through the Questions Asked While Designing." THES, Stanford, Mechanical Engineering.

Eris, O, N Martelaro, and P Badke-Schaub. 2014. "A Comparative Analysis of Multimodal Communication during Design Sketching in Co-Located and Distributed Environments." Design Studies 35 (6). Elsevier Ltd: 559-92. doi:10.1016/j.destud.2014.04.002.

Faems, Dries, and Annapoornima M Subramanian. 2013. "R\&D Manpower and Technological Performance: The Impact of Demographic and Task-Related Diversity." Research Policy 42 (9). Elsevier B.V.: 1624-33. doi:10.1016/j.respol.2013.06.001.

Gephart, W J, and D P Antonoplos. 1969. "The Effects of Expectancy and Other ResearchBiasing Factors." JOUR. The Phi Delta Kappan 50 (10): 579-83. http://www.jstor.org/stable/20372478.

Hansen, Z N L, Y Zhang, and S Ahmed-Kristensen. 2013. "Viewing Engineering Offshoring in a Network Perspective: Addressing and Managing Risks." Journal of Manufacturing Technology Management $24 \quad$ (2): http://www.emeraldinsight.com/journals.htm?articleid=17076811\&show=abstract.

Herbsleb, J D. 2007. "Global Software Engineering: The Future of Socio-Technical Coordination." In FoSE 2007: Future of Software Engineering, 188-98. doi:10.1109/FOSE.2007.11.

Hinds, P J, and M Mortensen. 2005. "Understanding Conflict in Geographically Distributed Teams: The Moderating Effects of Shared Identity, Shared Context, and Spontaneous Communication." Organization Science 16 (3): 290-307. doi:10.1287/orsc.1050.0122.

Hofstede, G, G J Hofstede, and M Minkov. 2010. Cultures and Organizations: Software of the Mind, Revised and Expanded 3rd Ed. BOOK. Vol. 3rd. New York, NY, USA: McGraw-Hill.

Hult, G T M, D J Ketchen, and S F Slater. 2004. "Information Processing, Knowledge Development, and Strategic Supply Chain Performance." JOUR. Academy of Management Journal 47 (2): 241-53.

Humayun, M, and C Gang. 2013. "An Empirical Study on Improving Shared Understanding of Requirements in GSD." International Journal of Software Engineering and Its Applications 7 (1): 79-92.

Johnson, T E, Y Lee, M Lee, D L O'Connor, M K Khalil, and X Huang. 2007. "Measuring Sharedness of Team-Related Knowledge: Design and Validation of a Shared Mental Model Instrument." Human Resource Development International 10 (4): 437-54. doi:10.1080/13678860701723802.

Johnson, T E, and D L O'Connor. 2008. “Measuring Team Shared Understanding Using the Analysis- Constructed Shared Mental Model Methodology." Performance Improvement Quarterly 21 (3): 113-34. doi:10.1002/piq.

Joshi, Aparna, and Hyuntak Roh. 2009. "The Role of Context in Work Team Diversity Research: A Meta-Analytic Review." Academy of Management Journal 52 (3): 599-627. doi:10.5465/AMJ.2009.41331491.

Kirk, R E. 2009. Experimental Design. BOOK. London, UK: Sage Publications. 
Kleinsmann, M, and R Valkenburg. 2008. "Barriers and Enablers for Creating Shared Understanding in Co-Design Projects.” Design Studies 29 (4): 369-86. doi:10.1016/j.destud.2008.03.003.

Ko, D-G, L J Kirsch, and W R King. 2005. "Antecedents of Knowladge Transfer from Consultants to Clients in Enterprise System Implementations." MIS Quarterly 29 (1): 59-85.

Kochan, T, K Bezrukova, R Ely, S Jackson, A Joshi, K Jehn, J Leonard, D Levine, and D Thomas. 2003. "The Effects of Diversity on Business Performance: Report of the Diversity Research Network.” JOUR. Human Resource Management 42 (1): 3-21.

Lanaj, K, J R Hollenbeck, D R Ilgen, C M Barnes, and S J Harmon. 2012. "The DoubleEdged Sword of Decentralized Planning in Multiteam Systems." Academy of Management Journal 56 (3): 735-57. doi:10.5465/amj.2011.0350.

Lau, D C, and J K Murnighan. 1998. "Demographic Diversity and Faultlines: The Compositional Dynamics of Organizational Groups." JOUR. Academy of Management Review 23 (2): 325-40.

Lawler, E J, and J Yoon. 1996. "Commitment in Exchange Relations: Test of a Theory of Relational Cohesion.” JOUR. American Sociological Review 61 (1): 89-108.

Lawson, B, K J Petersen, P D Cousins, and R B Handfield. 2009. "Knowledge Sharing in Interorganizational Product Development Teams: The Effect of Formal and Informal Socialization Mechanisms." Journal of Product Innovation Management 26 (2): 156-72. doi:10.1111/j.1540-5885.2009.00343.x.

Leidner, D E, and T Kayworth. 2006. "Review: A Review of Culture in Information Systems Research: Toward a Theory of Information Technology Culture Conflict." JOUR. MIS Quarterly 30 (2). Society for Information Management and The Management Information Systems Research Center: 357-99.

Levesque, L L, J M Wilson, and D R Wholey. 2001. "Cognitive Divergence and Shared Mental Models in Software Development Project Teams." Journal of Organizational Behavior 22 (2): 135-44. doi:10.1002/job.87.

Mamykina, L, L Candy, and E Edmonds. 2002. "Collaborative Creativity." Communications of the ACM 45 (10): 96-99. doi:10.1145/570907.570940.

Matveev, A V, and P E Nelson. 2004. "Cross Cultural Communication Competence and Multicultural Team Performance Perceptions of American and Russian Managers." JOUR. International Journal of Cross Cultural Management 4 (2): 253-70.

Maznevski, M L, and K M Chudoba. 2000. "Bridging Space over Time: Global Virtual Team Dynamics and Effectiveness.” JOUR. Organization Science 11 (5): 473-92.

McComb, S A. 2007. "Mental Model Convergence: The Shift from Being an Individual to Being a Team." Research in Multi-Level Issues 6 (7): 95-147. doi:10.1016/S14759144(07)06005-5.

McComb, S A, S G Green, and W Dale Compton. 1999. "Project Goals, Team Performance, and Shared Understanding." Engineering Management Journal 11 (3): 7-12.

Miron, E, M Erez, and E Naveh. 2004. "Do Personal Characteristics and Cultural Values That Promote Innovation, Quality, and Efficiency Compete or Complement Each Other?" JOUR. Journal of Organizational Behavior 25 (2): 175-99.

Mulder, I, J Swaak, and J Kessels. 2002. "Assessing Group Learning and Shared Understanding in Technology-Mediated Interaction." JOUR. Journal of Educational 
Technology \& Society 5 (1): 35-47. http://sfx4 exlibrisgroup.com:9003/bath?sid=google.

- 2004. "In Search of Reflective Behavior and Shared Understanding in Ad Hoc Expert Teams." Cyberpsychology \& Behavior 7 (2): 141-54. doi:10.1089/109493104323024410.

Novak, J D, and A J Cañas. 2008. "The Theory Underlying Concept Maps and How to Construct and Use Them." http://eprint.ihmc.us/5/.

O’Connor, D L. 2004. "Measuring Team Cognition: Concept Mapping Elicitation as a Means of Constructing Team Shared Mental Models in an Applied Setting." In First Int. Conference on Concept Mapping, edited by A J Cañas, J D Novak, and F M González, 1-7. Pamplona, Spain.

Oppl, S, and C Stary. 2013. "Facilitating Shared Understanding of Work Situations Using a Tangible Tabletop Interface." Behaviour \& Information Technology 33 (6). Taylor \& Francis: 619-35. doi:10.1080/0144929X.2013.833293.

Panteli, N, and S Sockalingam. 2005. "Trust and Conflict within Virtual Inter-Organizational Alliances: A Framework for Facilitating Knowledge Sharing." Decision Support Systems 39 (4): 599-617. doi:10.1016/j.dss.2004.03.003.

Preston, D S, E Karahanna, and F Rowe. 2006. "Development of Shared Understanding between the Chief Information Officer and Top Management Team in U.S. and French Organizations: A Cross-Cultural Comparison." IEEE Transactions on Engineering Management 53 (2): 191-206. doi:10.1109/TEM.2006.872244.

$\mathrm{Qu}, \mathrm{Y}$, and D L Hansen. 2008. "Building Shared Understanding in Collaborative Sensemaking." In Proceedings of the Workshop on Sensemaking at the Conference on Human Factors in Computing Systems (CHI), 1-5. Florence, Italy.

Robson, C. 2002. Real World Research. BOOK. Vol. 2nd. Chichester: Wiley. http://sfx4.exlibrisgroup.com:9003/bath?sid=google.

Salas, E, N J Cooke, and M A Rosen. 2008. "On Teams, Teamwork, and Team Performance: Discoveries and Developments." Human Factors: The Journal of the Human Factors and Ergonomics Society 50 (3): 540-47. doi:10.1518/001872008X288457.

Spee, A P, and P Jarzabkowski. 2009. "Strategy Tools as Boundary Objects Introduction." Strategic Organization 7 (2): 223-32.

Stenfors, S, L Tanner, and I Haapalinna. 2004. "Executive Use of Strategy Tools : Building Shared Understanding through Boundary Objects." In Frontiers of E-Business Research, 635-45.

Stewart-Williams, S. 2004. "The Placebo Effect: Dissolving the Expectancy versus Conditioning Debate." JOUR. Psychological Bulletin 130 (2): 324-40. http://sfx4.exlibrisgroup.com:9003/bath?sid=google.

Swaab, R I, T Postmes, and P Neijens. 2002. "Multiparty Negotiation Support: The Role of Visualization's Influence on the Development of Shared Mental Models." Journal of $\begin{array}{lllll}\text { Management } & \text { Information } & \text { Systems } & 19 & \text { (1): }\end{array}$ http://mesharpe.metapress.com/index/3YFQA3A8HYWGJWXD.pdf.

Tang, H H, Y Y Lee, and J S Gero. 2011. "Comparing Collaborative Co-Located and Distributed Design Processes in Digital and Traditional Sketching Environments: A Protocol Study Using the Function-Behaviour-Structure Coding Scheme." JOUR. Design Studies 32 (1). Elsevier Ltd: 1-29. doi:10.1016/j.destud.2010.06.004.

Torgerson, D J, and C J Torgerson. 2003. “Avoiding Bias in Randomised Controlled Trials in 
Educational Research.” JOUR. British Journal of Educational Studies 51 (1): 36-45. http://sfx4.exlibrisgroup.com:9003/bath?sid=google.

Walker, I. 2010. Research Methods and Statistics. BOOK. New York, USA: Palgrave Macmillan.

Wodehouse, A, and R Maclachlan. 2014. "An Exploratory Model for Understanding Culture in Student Design Team Idea Generation.” The Design Journal 17 (4). Routledge: 488514. 